\title{
Gestão da informação e do conhecimento em políticas públicas: ações realizadas pela rede CEDES/ME
}

\author{
Giselle Helena Tavares* \\ Gisele Maria Schwartz**
}

\begin{abstract}
Resumo: Os diálogos entre governo e Universidades nem sempre são estreitados, em função das dificuldades na democratização do conhecimento sobre as ações desenvolvidas. Sendo assim, este estudo, de natureza quantitativa, tem por objetivo realizar a gestão das informações e do conhecimento produzido relativo às ações da Rede CEDES/ ME. Dados provenientes de pesquisa documental e de campo foram descritivamente analisados, por meio da técnica de Análise de Conteúdo Temático e demonstraram que a Rede CEDES representa um potencial canal de diálogo entre o poder público e a sociedade, tendo um papel importante neste processo crítico.
\end{abstract}

Palavras-chave: organização \& administração. Informação.

Políticas Públicas. Esporte.

\section{INTRODUÇÃO}

Os estudos sobre a gestão do conhecimento e da informação no campo das organizações públicas vêm ganhando cada vez mais espaço no contexto acadêmico. Esta condição é devida à necessidade de se socializar as práticas realizadas na gestão pública. Os diálogos entre o governo e a Universidade vêm sendo entendidos como uma saída para a democratização do conhecimento, bem como, uma possibilidade de conscientização da população, a partir do acesso à informação. (SCHWARTZ, 2010a).

\footnotetext{
'Departamento de Educação Física.Instituto de Biociências. Universidade Estadual Paulista Júlio de Mesquita Filho (UNESP). Rio Claro, SP, Brasil. E-mail: gi_htavares@yahoo.com.br

"Departamento de Educação Física. Instituto de Biociências. Universidade Estadual Paulista Júlio de Mesquita Filho (UNESP). Rio Claro, SP, Brasil. E-mail: schwartz@rc.unesp.br
} 
A criação de uma Rede de ações no campo do esporte e lazer, como a Rede CEDES, parece ser uma estratégia interessante neste sentido, adotada pelo Ministério do Esporte e que merece um olhar mais atento. Os Centros de Desenvolvimento de Esporte Recreativo e de Lazer (Rede CEDES) se referem a uma ação política que surge para traçar relações sinérgicas entre centros produtores de pesquisa do país e o governo, em torno de uma demanda governamental, que tem como propósito, segundo Bonalume (2008, p.69) "[...] articular o conhecimento produzido para utilizá-lo na construção da política nacional.".

Entretanto, embora já se tenham pistas de que a Rede CEDES venha contribuindo no processo de produção de conhecimento, ainda não foi possível visualizar a organização deste conhecimento, mesmo dentro do próprio sistema organizacional da Rede CEDES, no Ministério do Esporte. O marco do momento atual é a necessidade da qualidade da circulação deste conhecimento, e, o mais importante, a aplicabilidade do mesmo, sendo este, o fato impulsionador deste estudo. Busca-se, a partir desta investigação, subsidiar as questões da gestão da informação e do conhecimento que envolve as ações da Rede CEDES, podendo contribuir para a continuidade de suas atuações e na geração de novas ações, no campo das Políticas Públicas de esporte recreativo e lazer no Brasil.

Sendo assim, o presente estudo tem por objetivo realizar a gestão das informações e do conhecimento produzido, decorrentes das ações realizadas pela Rede CEDES, no período de 2003 a 2010, analisando o conteúdo da produção dos núcleos e grupos componentes, evidenciados os principais resultados alcançados, bem como, lacunas e campos inexplorados no âmbito das Políticas Públicas de esporte e lazer no Brasil.

\section{MÉTOdo}

O estudo, de caráter qualitativo, foi caracterizado sendo composto por pesquisa documental e pesquisa de campo (GIL, 2002; RICHARDSON, 2007). Inicialmente, foi realizada uma revisão de 
literatura, com o intuito de buscar referenciais teóricos e conceituais. Em seguida, foi desenvolvida a Pesquisa Documental, diretamente in loco no Ministério do Esporte, sendo esta, adequada aos objetivos desse estudo, tendo em vista uma de suas importantes característica relativa a tratar de documentos usualmente pertinentes a arquivos de órgãos públicos e produções escritas.

Neste sentido, para o desenvolvimento da pesquisa documental foi realizada uma consulta ao acervo documental do Ministério do Esporte, obtendo-se, assim, acesso a todas as informações contidas nos relatórios de cumprimento do objeto, cadastro de produção e outros documentos alocados das dependências do ME, dos Núcleos e Grupos pertencentes à Rede. Esta análise documental foi realizada na Secretaria Nacional de Desenvolvimento do Esporte e do Lazer (SNDEL), Ministério do Esporte, localizado em Brasília, Distrito Federal, com a permanência da pesquisadora durante o período de 40 dias neste local.

Estes documentos eram exclusivamente enviados pelos pesquisadores ao $\mathrm{ME}$, como forma de relatório de cumprimento de objeto e outros documentos solicitados pelos gestores da Rede com intuito de organização interna sobre os financiamentos distribuídos. Além da vivência de todo o funcionamento da Rede, propiciado pela permanência da pesquisadora na SNDEL, foi possível, também, participar dos eventos organizados pela Rede CEDES, o que pode subsidiar a coleta de dados e auxiliar no entendimento sobre o funcionamento da mesma, podendo obter informações não contidas em documentos, ou seja, o conhecimento tácito dos envolvidos no processo, por meio de diálogos e observação do meio.

Além dos documentos enviados pelos pesquisadores, foram consultados tabelas, gráficos e levantamentos internos, realizados pelos funcionários da Rede, a fim de obter a organização deste material. Nestes documentos, foram consultadas as informações referentes às ações realizadas pela Rede CEDES, especificando-se as pesquisas e projetos desenvolvidos pelos grupos e núcleos, instituições envolvidas, intervenções, grupos de estudos, publicações. 
Além disso, foram levantados outros apoios financeiros partindo da Rede CEDES, como aqueles dados aos periódicos e eventos científicos.

Posteriormente, foi realizada uma pesquisa de campo, utilizando como instrumento para a coleta de dados a técnica de questionário misto, aplicado a uma amostra intencional composta pelos coordenadores dos núcleos e grupos pertencentes à Rede CEDES, com o intuito de coletar informações não contidas nos relatórios do ME. Os dados foram analisados descritivamente, por meio da Técnica de Análise de Conteúdo Temático (BARDIN, 2010). Esta técnica prevê a categorização em eixos, de acordo com as abordagens mais dominantes e emergentes, identificadas a partir da revisão de literatura.

\section{Resultados e discussão}

Com base nos resultados obtidos pela Análise de Conteúdo, pode-se perceber que, em relação ao primeiro eixo referente aos CAMINHOS PERCORRIDOS PELA REDE CEDES/ME, a coleta de dados realizada no ME permitiu acesso a documentos, os quais, até este momento, não haviam sido socializados e divulgados. Este fato foi um dos motivadores para a realização desta coleta nas dependências no ME, para que fosse possível ter acesso a todas as informações oficiais referentes à Rede CEDES e, além disso, poderse compreender toda a sua estrutura e funcionamento.

Foram analisados os relatórios de cumprimento de objeto enviados como prestação de contas ao final dos convênios firmados, com o intuito de se arquivar as informações sobre o desenvolvimento dos projetos. Entretanto, este documento, apesar de ser uma prestação de contas obrigatória prevista por lei, para todos os projetos relacionados ao poder público, não foi possível localizar todos os relatórios dos convênios firmados nas dependências do ME. Além disso, estes não seguiam um modelo preestabelecido, levando a uma grande dificuldade para a coleta dos dados. 
Com base nesses entraves estruturais, para a análise proposta neste artigo, foi possível ter acesso a 57 relatórios e 70 Cadastros de Produção, ainda que o número de projetos financiados fosse 129. Além disso, foram consultados todos os projetos enviados para a concorrência pública nos editais, a partir do ano de 2007, onde se teve acesso a um total de 79 projetos.

Diante desta defasagem, mais uma iniciativa foi feita, no sentido de realizar a gestão das informações relacionadas com a Rede CEDES. Para a realização deste trabalho, foi enviado um questionário misto, a todos os coordenadores de projetos, tendo sido obtidas apenas 59 respostas, de um total de 107.

A partir dos documentos analisados evidenciou-se que, do total de 129 convênios firmados e 208 pesquisas desenvolvidas, durante o período de 2003 a 2010, a forma de concessão das pesquisas passou por momentos diferentes. No período inicial da criação da Rede (2003 a 2006), sob a gestão do Professor Doutor Lino Castellani Filho, grupos de pesquisas na área de estudos sobre Políticas Públicas de esporte e lazer eram convidados a desenvolver pesquisa, sob demanda temática indicada pelo $\mathrm{ME}$, em reunião com alguns professores, os quais faziam parte de um conselho.

A partir de 2007, sob a gestão da Professora Mestre Rejane Penna Rodrigues, foi implementada a política de edital público, sendo, o primeiro, realizado com temáticas oriundas de sugestão dos pesquisadores e a partir de demandas temáticas identificadas pelo ME. Além destas modalidades de concessão, existia, ainda, a possibilidade de realização de pesquisas induzidas, sendo estas, demandas especiais do ME, que deveriam ser realizadas por grupos específicos, com tradição na área de desenvolvimento do projeto.

Este momento da Rede, em 2010, foi marcado pela preocupação com a gestão do conhecimento produzido. Sendo assim, foram realizadas algumas ações neste sentido, como a elaboração do Repositório da Rede CEDES (RIRC) e, para o subsídio do mesmo, uma pesquisa induzida sobre o Balanço da Produção da Rede 
CEDES (SCHWARTZ, et al. 2010), sendo que parte desse Balanço já era referente ao desenvolvimento deste estudo.

Entretanto, apesar de todos estes entraves, Starepravo, Souza, Marchi Junior (2011) salientam que o tema sobre Políticas Públicas de esporte e lazer no Brasil, vem ganhando destaque nos últimos anos, dentro do campo científico/acadêmico da Educação Física. Este fato é comprovado pelas várias ações desenvolvidas pelo ME, ao completar um ciclo de oito anos de existência:

[...] seja através da criação de uma Rede que apoia diretamente esse lócus de pesquisa, pela implementação de Políticas Públicas ditas inovadoras, pela possibilidade dada de participação dos diferentes grupos sociais na formulação dessas políticas, ou ainda por ter 'abraçado a causa' da realização de megaeventos esportivos do país. (STAREPRAVO, SOUZA, MARCHI JUNIOR, 2011, p.233).

No que concerne ao segundo eixo da pesquisa, referente à Gestão da Informação, Políticas Públicas e Universidades: Possibilidade para um Caminho de Mudanças, os resultados apontaram, a partir da análise destes documentos, que, desde o ano de 2003 até o ano de 2010, foram firmados 129 convênios, envolvendo 208 pesquisas. Estes dados não corroboram aqueles encontrados no site do ME, evidenciando a dificuldade de organização destes dados. Nota-se uma incoerência interna na disseminação dos próprios resultados da Rede.

Devido à dificuldade de padronização dos dados encontrados nos documentos, não foi possível obter, ainda, resultados reais, sobre número de pesquisadores e estudantes atendidos. Os dados elencados neste trabalho são fruto de uma busca incessante aos documentos alocados no ME. Foi possível contabilizar um número total de 1128 envolvidos, sendo 293 doutores, 172 mestres, 652 bolsitas de graduação, técnicos, mestrado e doutorado, e 11 voluntários. Estes pesquisadores eram, em sua maioria, da área da Educação Física, seguidas das áreas de Educação e Ciências Sociais em sua formação inicial (CONSELHO..., 2013) 
Além disso, para a realização dos convênios, estão vinculadas à Rede CEDES um total de 59 instituições, sendo 55 públicas e 4 privadas, distribuídas por todas as regiões do país. Somente a partir de 2006 a concessão de convênios pode ser estendida a Instituições de Ensino Superior (IES) privadas. Neste sentido, foi possível observar um número significativamente maior de apoio a instituições públicas, devido ao apoio direcionado inicialmente pela Rede as instituições públicas.

No que se refere ao atendimento às diferentes regiões do país, foi possível evidenciar que o processo foi gradual. Os resultados apontam que as pesquisas financiadas que focalizavam o campo do lazer e esporte recreativo estão concentradas, principalmente, nas Regiões Sul e Sudeste. Estes dados traduzem um panorama nacional econômico-social de monopólio destas duas Regiões, em comparação às outras, podendo ser decorrente do fato de que, no que tange ao aspecto das pesquisas, estas regiões representam os locais onde está sediada a maioria das Universidades públicas e particulares do país.

Além disto, também é encontrada, nessas regiões, uma grande quantidade de grupos de pesquisas vinculados ao Diretório de Grupos de Pesquisa do Conselho Nacional de Desenvolvimento Científico e Tecnológico $(\mathrm{CNPq})$. Este fato evidencia uma produção constante dos coordenadores e pesquisadores desses grupos, uma vez que, inclusive, muitos deles estão vinculados a programas de PósGraduação, o que infere a tendência de grande produtividade de pesquisas realizadas de maneira constante.

Na visão de Mascarenhas (2005), para que mudanças sociais efetivas aconteçam, são necessárias condições objetivas e subjetivas, que dependem da realidade contextual e do momento histórico. Neste sentido, a utilização de estratégias em que grupos sociais afins se unem de maneira organizada, de modo a intervirem diretamente no contexto onde vivem, pode ser um poderoso instrumento e forte mobilizador para a transformação de uma sociedade. 
No período de 2003 até 2010, a Rede CEDES contou com a participação de 96 grupos de estudos vinculados ao Diretório de Grupos de Pesquisas do CNPq. Estes grupos pertencem a diferentes áreas, sendo a Educação Física a área predominante, seguida de Educação e Turismo.

Estes dados corroboram a pesquisa realizada por Tavares et al.. $(2011)^{1}$, na qual os autores destacam o caráter interdisciplinar dos estudos do lazer e do esporte recreativo, bem como, a maior prevalência dos grupos nestas áreas (Educação Física, Educação e Turismo). Ainda sobre esta questão, em pesquisa realizada por Souza e Isayama (2006) foi evidenciado um total de 81 grupos de estudos até esse ano. Estes dados, quando comparados à pesquisa realizada por Schwartz et al.. (2012) $)^{2}$, em que foram levantados 162 grupos de pesquisa no ano de 2009, 184 no ano de 2010, 208 no ano de 2011 e 223 no ano de 2012, foi possível evidenciar que houve um aumento significativo no número de grupos de pesquisas que estudam a temática do lazer e esporte recreativo. O incentivo dado pela Rede CEDES, ao contemplar um dos seus objetivos, que é a criação de novos grupos de pesquisas e a consolidação dos já existentes, pode ter sido um fator motivador deste aumento expressivo.

A partir dos documentos analisados, foi possível verificar a publicação de 108 livros, 80 capítulos de livros, 226 artigos (em periódicos e em anais) e 317 resumos como evidenciado na Figura $1:$

\footnotetext{
'TAVARES, G. H. A pesquisa no campo do lazer. Palestra apresentada no Encontro institucional: docência, pesquisa e extensão na recreação e no lazer, encontro nacional de recreação e lazer, 23.,2011. Avaré, SP.

${ }^{2}$ SCHWARTZ, G. M. Lazer como Campo de Estudos e Intervenção da Educação Física. Palestra apresentada no Congresso Ciências do Desporto e Educação Física dos Países de Língua Portuguesa, 14.,2012, Belo Horizonte
} 
Figura 1 - Publicações oriundas dos financiamentos da Rede CEDES

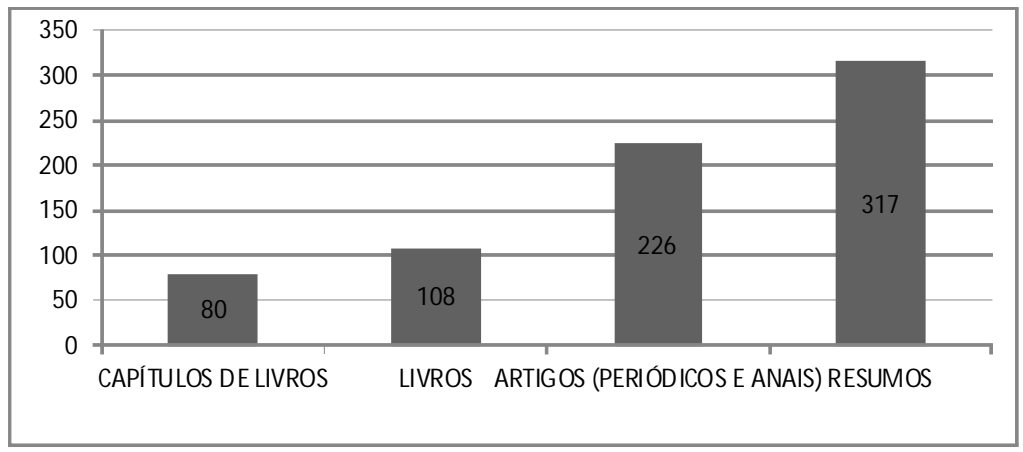

Fonte: Coletas de dados SNDEL

Foi possível observar um número expressivo de produções científicas, no que se referem aos artigos (em anais e em periódicos), livros e capítulo de livros. Conforme salientou Leydesdorff e Meyer (2006), a transferência do conhecimento, ciência e tecnologia à sociedade é de fundamental importância, tanto para a própria Universidade, quanto para a sociedade e para o governo. Neste sentido, a Universidade deve ter um papel de protagonista nas relações como o governo e sociedade, podendo, assim, subsidiar a criação de políticas eficientes e efetivas.

De acordo com Demo (1996, p.87), a pesquisa científica pode assumir um papel importante, podendo, assim, impactar diretamente o plano social e as ações dos gestores nos programas de governo. Marcellino (2008) ressalta que a sociedade vive, atualmente, na crise do conhecimento. Para este autor, ainda que já existam várias teorias deste conhecimento, pouco se sabe sobre como conhecê-lo. O desafio maior, neste sentido, é tentar trazer para o cotidiano social os saberem que, ainda, continuam concentrados dentro das Universidades.

Uma das questões mais relevantes, no que diz respeito às ressonâncias do apoio da Rede CEDES, se refere ao fato de que estas políticas proporcionam à comunidade acadêmica, professores e alunos envolvidos, a possibilidade de serem atores da construção dessa história, podendo transformar a realidade na qual estão inseridos, por meio das contribuições oriundas de suas pesquisas e 
projetos desenvolvidos. Esta representa uma das formas de intervenção da gestão participativa (BARBOSA, 2006), que tem como característica superar o centralismo das decisões e descentralizar o poder advindo de quem governa. Neste sentido, os produtos e desdobramentos das pesquisas da Rede CEDES podem contribuir, efetivamente, para a participação crítica e criativa destes atores, sendo, por intermédio da disseminação destas publicações, uma forma prática e disponível ao acesso de todos, para que se ampliem as reflexões acerca da Políticas Públicas no país.

Vale destacar ainda, a importância destas pesquisas para o subsídio das Políticas Públicas do Brasil, bem como, o papel dos pesquisadores como agentes participativos nesta questão. É necessário que fique claro, que o apoio da Rede CEDES, no que tange ao financiamento de pesquisas, não busca somente fomentar a produção científica da área, mas sim, que estas pesquisas, sirvam, efetivamente, para a melhoria das Políticas Públicas brasileiras. Para tanto, os pesquisadores envolvidos neste sistema, devem estar cientes do seu papel, na construção de uma política justa, que apresente relevância social e que atenda à população em geral.

O estreitamento das relações entre poder público e Universidade, possibilitado pelas ações da Rede CEDES, vai ao encontro da teoria formulada por Etzkowitz e Leydesdorff (2006), conhecida como tríplice hélice twins. $\mathrm{O}$ argumento desta teoria é baseado na tese de que a universidade tem um papel preponderante na sociedade baseada no conhecimento.

No desenvolvimento desta teoria no Brasil, Senhoras (2008, p.142) utilizou o termo "hélice tripla público-social", para se referir à HT twins ou sustentável. Neste modelo, o formato estratégico pressupõe, que o sistema público de pesquisa e de ensino superior "[...] deve responder às necessidades sociais específicas de forma ativa, com preocupação e comprometimento da agenda de ensino, pesquisa e extensão para a solução de problemas locais, regionais e nacionais de inclusão social." (SENHORAS, 2008, p. 142). A partir 
do apoio financeiro do governo federal, foi possível evidenciar que a Universidade tem entendido e absorvido o papel de efetivar a transferência de conhecimento para a sociedade.

No que tange às produções científicas oriundas da Rede CEDES, estas tiveram, em sua maioria, um foco nas análises da dimensão política na qual estão envolvidos. Entretanto, foi possível evidenciar a atenção dada por alguns estudiosos, no sentido de se compreender o sistema público que sustenta as questões do esporte e do lazer. Este aspecto é justificado pelo fato de que as linhas desenvolvidas nos projetos estavam sob a demanda do próprio ME. Foram evidenciados poucos estudos que abordassem a avaliação dos programas existentes.

Em uma investigação realizada por Amaral e Pereira (2009) foi possível demonstrar que, nos estudos sobre Políticas Públicas, a maior incidência segue a tendência de abordagem no que diz respeito à dimensão material policy (em relação à sociedade política), contendo poucos estudos que enfocam o aspecto politics (sistema público). As autoras ainda enfatizaram a ausência de rigorosidade conceitual, sendo, a maioria dos estudos realizados como relatos de experiência.

Santos, Batista e Araújo (2007) reafirmam esta tendência. Em pesquisa realizada sobre as temáticas dos estudos apresentados e publicados no GTT de Políticas Públicas do CBCE, foram evidenciadas três temáticas recorrentes, sendo eles: estudos que analisam e avaliam programas e projetos de educação física, esporte e lazer; relatos de experiência de programas e projetos em educação física, esporte e lazer; estudos sobre concepções e/ou teorias que embasam o campo da política pública para educação física, esporte e lazer.

Starepravo, Nunes e Marchi Junior (2009) ressaltam que, nos trabalhos que apresentam maior consistência teórica, as abordagens se debruçam na crítica ao neoliberalismo. Ou seja, o modo de entendimento da postura do Estado com relação ao esporte e ao lazer, corrobora aos dados encontrados no presente estudo. 
Os artigos provenientes das pesquisas financiadas pela Rede CEDES, foram publicados em diferentes revistas, sendo, em sua maioria, revistas nacionais. Em estudo realizado por Amaral e Pereira (2009), foi possível evidenciar a maior incidência de publicações sobre políticas públicas nas revistas Movimento, Revista Brasileira de Ciências do Esporte, Motrivivência, indo ao encontro dos periódicos nos quais as produções oriundas do apoio da Rede CEDES, foram publicadas (FONTE: DOCUMENTOS SNDEL).

Um dado interessante, que merece atenção neste momento, é referente à melhoria da classificação de alguns desses periódicos no Qualis Capes. Algumas dessas revistas são apoiadas pela Rede, tendo grande incidência de publicações oriundas das pesquisas desenvolvidas. O quadro a seguir representa a evolução da classificação das revistas, a partir da análise comparativa do estrato das últimas duas avaliações trienais, realizadas por Schwartz (2012). As revistas evidenciadas foram selecionadas a partir de uma pesquisa realizadas por meio da Plataforma Lattes, sobre a maior incidência de publicações em revistas, por pesquisadores coordenadores de grupos de pesquisas da área do lazer e esporte recreativo.

Figura 2 - Comparativo do estrato das duas últimas avaliações do Qualis Capes

\begin{tabular}{|l|c|c|}
\hline \multicolumn{1}{|c|}{ PERIÓDICOS } & QUAL IS ATÉ 2011 & QUAL IS 2012 \\
\hline The FIEP Bulletin & B4 & B4 \\
\hline Lécturas: Ed. Física y Deportes & B4 & C \\
\hline Revista Brasileira de Ciências do Esporte & B2 & B1 \\
\hline Licere & B3 & B2 \\
\hline Movimento (Porto Alegre) & B1 & A2 \\
\hline Motrivivência & B5 & B2 \\
\hline Coleção Pesquisa em Educação Física & B5 & B4 \\
\hline Revista da Educação Física/UEM & B2 & B2 \\
\hline Revista Brasileira de Atividade Física e Saúde & B2 & B2 \\
\hline Motriz & B1 & A2 \\
\hline Pensar a Prática (UFG) & B3 & B2 \\
\hline Motus Corporis (UGF) & B5 & B4 \\
\hline Revista Mineira de Educação Física & B4 & B4 \\
\hline Revista B rasileira de Ciências e Movimento & B2 & B2 \\
\hline Conexões (UNICAMP) & B4 & B4 \\
\hline
\end{tabular}


A partir deste dado, é possível afirmar que a Rede CEDES foi coadjuvante no processo que impulsionou a valorização das revistas da área do lazer e esporte recreativo. A defasagem no que se refere a periódicos específicos sobre essa temática, bem avaliados na área, sempre foi uma questão relevante neste campo de estudo. Melo e Werneck (2003) destacam que, para que haja uma evolução dos estudos do lazer, são necessárias algumas iniciativas, sendo, uma delas, possibilitar a socialização e o registro de todo o conhecimento produzido, por meio da constituição de grupos de pesquisa e investimentos do poder público, no sentido de financiar a política editorial e de possibilitar e facilitar o acesso às informações. Esta parece ser uma das contribuições efetivas da Rede no panorama atual das pesquisas sobre o lazer no Brasil, no que tange à produção e difusão de conhecimentos voltados para o aperfeiçoamento e à qualificação de projetos, programas e Políticas Públicas de esporte recreativo e de lazer.

Notou-se uma discrepante participação em eventos comparados à produção de artigos. Entretanto, cabe ressaltar que, a partir das linhas norteadoras e objetivos da Rede CEDES, é possível evidenciar que esta rede de ações busca subsidiar a elaboração das Políticas Públicas de esporte e lazer e os eventos da área podem ser considerados excelentes polos disseminadores e, ainda, um ambiente profícuo para discussões de problemas e estratégias para mudanças.

Bourdieu (1994) considera a divulgação de pesquisas como uma estratégia de legitimação do conhecimento no campo da pesquisa. Para este autor, os eventos científicos podem ser um espaço privilegiado de discussões, em que pesquisadores disseminam suas ideias, análises e conclusões, possibilitando um campo de debate entre os pesquisadores envolvidos na área.

$\mathrm{Na}$ busca da difusão do conhecimento produzido, as ações da Rede CEDES têm estabelecido interface com o fomento a eventos científicos e auxílio a periódicos, na edições e distribuição de materiais de divulgação científica. Esta estratégias, dentre outras, possibilita a participação dos atores nos processos de (re)alimentação das atividades decisórias e debates, que buscam a reflexão da ação vivida 
na gestão pública de esporte e lazer. No que se refere ao apoio a eventos, foram evidenciados subsídios a diversos periódicos e eventos, em todo o período de 2003 a 2010 (FONTE: DOCUMENTOS SNDEL).

Sobre estas ações, Bonalume (2011, p. 4), explicita que:

[...] o desenvolvimento de ações integradas implica em ideias como parceria e solidariedade, que requerem o conhecimento do outro e das demandas que enfrentam juntos. Além disso, a capacidade de gerir ações coletivas, de aglutinar aspirações, valores e estratégias, valorizando as diferenças e as relações constituídas, atentas aos problemas enfrentados e às alternativas encontradas.

Estas ações integradas podem ser observadas, quando se evidenciam os resultados apresentados por Starepravo, Nunes e Marchi Junior (2009), em seus estudos sobre a produção do GTT de Políticas Públicas, nos anais do XV Congresso Brasileiro de Ciências do Esporte (CONBRACE). Foi possível evidenciar a publicação de 28 trabalhos, sendo estes, 13 oriundos do apoio a pesquisas da Rede CEDES. Com este estudo, os autores puderam afirmar que, quantitativamente, o apoio dado por este programa parece fomentar o aumento das produções acerca da temática de Políticas Públicas de esporte e lazer. Conforme esses autores evidenciam, "[...] este pode ser um fator positivo, haja vista que o governo vem tendo uma atuação que estimula a produção no interior dos grupos de pesquisa sobre a temática." (STAREPRAVO; NUNES; MARCHI JUNIOR, 2009, p.4).

A ideia de Rede exposta por Bonalume (2008) depende da qualidade da conectividade, como capacidade estrutural de facilitar a comunicação entre os atores envolvidos, podendo compartilhar interesses e objetivos comuns. Para tanto, Marcellino (1996) busca refletir sobre a inserção de Políticas Públicas que pudessem favorecer a universalização das informações sobre os direitos, para todos os interessados, inclusive as camadas não atendidas da sociedade. 


\section{Considerações FINAIS}

A partir dos dados apresentados, foi possível evidenciar que as ações da Rede CEDES, apesar de efetivas, ainda não contemplam todas as necessidades, no que se refere à gestão das informações existentes. Em contrapartida, foi possível evidenciar também, que esta Rede possibilitou, aos atores sociais, expressarem suas opiniões por meio de publicações cientificas, problemas relacionados à área do esporte e do lazer, subsidiando novas propostas. Esta representa, consequentemente, uma estratégia interessante, no que diz respeito ao retorno dado pela sociedade sobre as iniciativas realizadas pelos governos.

Os dados demonstraram, ainda, que a Rede CEDES é um potencial canal de diálogo entre o poder público e a sociedade, tendo a Universidade e seus atores, um papel importante neste processo crítico, de aproximação entre a teoria e prática nestes campos de ação. Esta iniciativa evidencia a estratégia em que a Universidade, por meio da pesquisa, se torna protagonista no processo de decisão política, auxiliando na perspectiva de mudanças ideológicas, para as quais, geralmente, se coloca a responsabilidade apenas nos governos.

Segundo DaCosta (2009) o êxito das Políticas Públicas está diretamente relacionado com o diálogo entre as pessoas envolvidas e o total conhecimento da realidade onde estão inseridos. O apoio dado às Universidades para a difusão das pesquisas parece ser uma estratégia relevante no resultado positivo como geradora do crescimento, da divulgação e proliferação dos estudos do âmbito do esporte recreativo e do lazer em todo o território nacional. A gestão da informação e do conhecimento, entretanto, deve ser aprimorada, para servir como estratégia eficiente neste sentido.

$\mathrm{O}$ acesso a documentos concretos para o levantamento dos dados foi um fator limitante para a realização deste estudo, haja vista a dificuldade em se encontrar dados reais que subsidiassem 
adequadamente as discussões. Sendo assim, sugere-se o desenvolvimento de novas investidas em forma de pesquisas e de ações políticas envolvendo a Rede CEDES, no sentido de melhor compreender as lacunas advindas deste apoio governamental e subsidiar a gestão da informação e do conhecimento sobre esporte recreativo e lazer no país. 
Information management and knowledge in public policy: actions taken by rede CEDES/ME Abstract: Dialogues between Government and the Universities are not always narrowed due to the difficulties in the democratization of knowledge about the developed actions. Therefore, this quantitative study aims to manage the information about the actions performed by network CEDES, from Ministry of Sports. Data from documental research and exploratory research were descriptively analyzed by Content Analysis Technique and evidenced that network CEDES represents a potential channel for dialogue between Government and society, having an important role in this critical process.

Keywords: organization \& administration. Information. public policies. Sports.

Gestión de la información y del conocimiento en la política pública de las acciones tomadas por la red CEDES / ME

Resumen: Los diálogos entre el gobierno y las universidades no siempre se estrechan debido a las dificultades para la democratización del conocimiento acerca de las medidas adoptadas. Por lo tanto, este estudio cuantitativo, tiene como objetivo gestionar la información sobre las acciones llevadas a cabo por la Red de CEDES / ME. Los datos de la investigación documental y de campo fueron analizados descriptivamente mediante la técnica de análisis de contenido y demostró que la Red CEDES representa un posible canal de diálogo entre el gobierno y la sociedad, que tiene un papel importante en este proceso crítico.

Palabras clave: organización \& administración. Información. Políticas Públicas. Deportes. 


\section{REFERÊNCIAS}

AMARAL, S. C. F; PEREIRA, A. P. C. Reflexões sobre a produção em Políticas Públicas de Educação Física, esporte e lazer. Revista Brasileira de Ciências do Esporte, Campinas, v. 31, n. 1, p. 41-56, set. 2009. Disponível em: < http:// www.rbceonline.org.br/revista/index.php/RBCE/article/view/631>. Acesso em 5 ago. 2012.

BARBOSA, L. P. Significados do terceiro setor: de uma nova prática política à despolitização da questão social. Sociedade e Cultura, Goiânia, v. 9, n. 1, p.173186, jan./jun.2006. Disponível em: < http://www.revistas.ufg.br/index.php/fchf/ article/view/227/194 >. Acesso em: 5 dez. 2011.

BARDIN, L. Análise de conteúdo. ed. rev. atual.. Lisboa: Edições70, 2010.

BONALUME, C. R. A Rede CEDES como uma rede de política pública. In: PINTO, L. M. S. M.; SILVA, D. A. M.; RODRIGUES, R. P.; BONALUME, C. R.; ARAÚJO, L. R. M. (Org.). Brincar, jogar, viver: lazer e intersetorialidade com o PELC. Cidade: Gráfica e Editora América, 2008. p. 68-91.

BONALUME, C. R. O paradigma da intersetorialidade nas Políticas Públicas de esporte e lazer. Licere, Belo Horizonte, v. 14, n. 1, mar. 2011. Disponível em: < http://www.anima.eefd.ufrj.br/licere/pdf/licereV14N01_ar1.pdf>. Acesso em: 7 dez. 2011.

BOURDIEU, P. Sociologia. Renato Ortiz (Org.). 2 ed. São Paulo: Ática, 1994.

CONSELHO NACIONAL DE PESQUISA. Plataforma Lattes. Disponível em: <http:/ /lattes.cnpq.br/index.htm>. Acesso em: 22 abr. 2013

DaCOSTA, L. P. Aplicando a gestão do conhecimento na renovação do esporte no Brasil. In. OLIVEIRA, A. F. S. Gestão do conhecimento para coleta de dados e diagnósticos sobre esporte e atividade física em perspectiva nacional. Edição do Autor, 2009. Disponível em:< http://cev.org.br/arquivo/biblioteca/gestaoconhecimento-para-coleta-dados diagnosticos-sobre-esporte-atividade-fisicaperspectiva-nacional.pdf >. Acesso em: 15 ago. 2012.

DEMO, P. Pesquisa e construção do conhecimento: metodologia científica no caminho de Habermas. Rio de Janeiro: Tempo Brasileiro, 1994.

ETZKOWITZ, H.; ZHOU, C. Triple Helix twins: innovation and sustainability. Science and Public Policy, Londres, v. 33, n. 1, p. 77-83, 2006. Disponível em: <http:// www.ingentaconnect.com/content/beech/spp/2006/00000033/00000001/ art00007>. Acesso em: 12 out. 2011.

GIL, A. C. Como classificar as pesquisas? In: GIL, A. C. Como elaborar projetos de pesquisa. 4. ed. São Paulo: Atlas, 2002. p. 41-58.

MASCARENHAS, F. Lazer e utopia: limites e possibilidades de ação política, Movimento, Porto Alegre, v. 11, n. 3, p. 155-182, set/dez, 2005. 
MARCELLINO, N. Estudos do lazer: Uma introdução. Campinas, SP; Autores associados, 1996.

MARCELlinO, N. C. (Org.) Políticas Públicas de lazer. Campinas: Alínea, 2008.

MELO, V. A.; WERNECK, C. L. G. Lazer no Brasil: trajetória de estudos, possibilidades de pesquisa. Movimento, Porto Alegre, v.9, n.1, p.23-44, jan/abr, 2003.

NONAKA, I.; TAKEUCHI, H. Criação do conhecimento na empresa. Tradução de Ana Beatriz Rodrigues e Priscilla Martins Celeste. Rio de Janeiro: Campus, 1997.

RICHARDSON, R. J. Pesquisa social: métodos e técnicas. 3 ed. São Paulo: Atlas, 2007.

SANTOS , A. L. F.; BATISTA, M. C. A.; ARAÚJO, A. V. A produção do conhecimento em política pública para educação física, esporte e lazer: o GTT 10 em Pernambuco. In: CONGRESSO BRASILEIRO DE CIÊNCIAS DO ESPORTE, 14. E CONGRESSO INTERNACIONAL DE CIÊNCIAS DO ESPORTE, 2., 2007, Olinda. Anais... Campinas: Colégio Brasileiro de Ciências do Esporte, 2007. v.1. p.1-10.

SCHWARTZ, G. M.; SANTIAGO, D. R. P. ; KAWAGUTI, C. N. ;TAVARES, G. H. FIGUEIREDO, J. P.; NAZÁRIO, M. E. S. Gestão da Informação sobre lazer e esporte recreativo: Balanço da Rede CEDES. Várzea Paulista: Fontoura, 2010. $192 \mathrm{p}$.

SCHWARTZ, G. M. Reflexões e Sugestões acerca do conteúdo da produção da Rede CEDES de 2003 a 2010. In: SCHWARTZ, G. M, SANTIAGO, D. R. P. KAWAGUTI, C. N. TAVARES, G. H. FIGUEIREDO, J. P. NAZÁRIO, M. E. S. Gestão da Informação sobre lazer e esporte recreativo: Balanço da Rede CEDES, 1 ed. Várzea Paulista: Fontoura, 2010a. p.129-142.

SENHORAS, E. M. As redes do desenvolvimento Econômico e Social no Sistema de Ensino Superior Brasileiro. Liinc em Revista, Rio de Janeiro, v.4, n.1, p. 138-153, 2008. Disponível em http://revista.ibict.br/liinc/index.php/liinc/article/viewFile/258/ 149. Acesso em: 12 set. 2011.

SOUZA, A. P. T.; ISAYAMA, H. F. Lazer e educação física: análise dos grupos de pesquisa em lazer cadastrados na plataforma Lattes do CNPq. Lecturas, Educación Física y Deportes, Revista Digital, Buenos Aires, v. 11, n. 9. 2006. Disponível em: < http://www.efdeportes.com/efd99/cnpq.htm >. Acesso em: 12 mar. 2010.

STAREPRAVO, F. A.; NUNES, R. J. S.; MARCHI JÚNIOR, W. Agenda de pesquisa em Políticas Públicas de esporte e lazer: uma leitura a partir do GTT de Políticas Públicas no XV Congresso Brasileiro de Ciências do Esporte. In: CONGRESSO BRASILEIRO DE CIÊNCIAS DO ESPORTE, 15., CONGRESSO INTERNACIONAL DE CIÊNCIAS DO ESPORTE, 3., 2009, Salvador. Anais... Salvador: Colégio Brasileiro de Ciências do Esporte, 2009. v.1, p.1-14. 
STAREPRAVO, F. A., SOUZA J, MARCHI JUNIOR, W. Políticas Públicas de Esporte e Lazer no Brasil: Uma Proposta Teórico-Metodológica de Análise, Movimento, Porto Alegre, v. 17, n. 3, p. 233- 251, jul/set de 2011. Disponível em: < http:// seer.ufrgs.br/Movimento/article/view/18420. Acesso em 12 jul 2012.

WERNECK, C. L. G. A constituição do lazer como um campo de estudos científicos no Brasil: implicações do discurso sobre a cientificidade e autonomia deste campo. In: ENCONTRO NACIONAL DE RECREAÇÃO E LAZER, 12., 2000, Balneário Camboriú. Coletânea... Balneário Camboriú: Roca/Universidade do Vale do Itajaí, 2000. p. 77-88.

Financiamento: Coordenação de Aperfeiçoamento de Pessoal de Nível Superior (CAPES)

Endereço para correspondência:

LEL- Laboratório de Estudos do Lazer/ DEF/IB

Campus Rio Claro

Universidade Estadual Paulista Júlio de Mesquita Filho (UNESP)

Rua 24 A, n. 1515

Bela Vista

13506-900 - Rio Claro, SP - Brasil

Recebido em: 15.04.2013

Aprovado em: 08.08.2013

Movimento, Porto Alegre, v. 19, n. 04, p.207-226, out/dez de 2013. 